\title{
Delayed presentation of Boerhaave's syndrome
}

\author{
Mohamad Atie, ${ }^{1}$ Graham Dunn, ${ }^{2}$ Gregory L Falk ${ }^{1}$
}

'Department of Upper Gl Surgery, Concord Repatriation General Hospital, Concord, New South Wales, Australia ${ }^{2}$ Department of Radiology, Concord Repatriation General Hospital, Concord, New South Wales, Australia

\section{Correspondence to}

Mohamad Atie,

moatiemd@yahoo.com

Accepted 29 September 2016

\section{DESCRIPTION}

A 45-year-old, cognitively impaired, morbidly super obese male patient is described with a delayed presentation of Boerhaave's syndrome. The patient had been mistakenly treated elsewhere for an empyema of the left thorax. The primary diagnosis had been based on a chest X-ray revealing hydropneumothorax and a thoracocentesis that delivered pus. The patient was transferred to our tertiary care unit, 5 days after initial presentation, following deterioration of his condition. The patient was in multiorgan failure requiring highdose inotropes and mechanical ventilation. CT scan of the chest, abdomen and pelvis revealed a defect in the mid-oesophageal wall (figure 1: black arrow $=$ defect in oesophageal wall) with extravasation of nasogastric tube administered contrast into the left chest cavity (figures 1 and 2: $\mathrm{C}=$ contrast in pleural cavity). The left lung was severely collapsed, and intrapleural space food was present (figures 1 and 2: $\mathrm{C}=$ contrast in pleural cavity, $\mathrm{L}=$ lung and $\mathrm{D}=$ food debris in pleural space). The patient was unstable for surgery. Endoscopy was performed in ICU, and the nasogastric tube tip was positioned at the level of the defect for continuous irrigation. Two large radiological chest drains were inserted. This management stabilised the patient's condition. Thoracotomy, decortication, T-tube oesophagostomy through the defect, appropriate drainage, tracheostomy and feeding jejunostomy were performed. Contrast study 8 weeks later did not show any leak. All tubes were removed. The patient was discharged home on soft diet.

Boerhaave's syndrome is associated with high mortality and morbidity. ${ }^{1}$ Prompt diagnosis and assessment with soluble contrast swallow coupled with endoscopy are the established standard. We prefer CT scan of the thorax, abdomen and pelvis

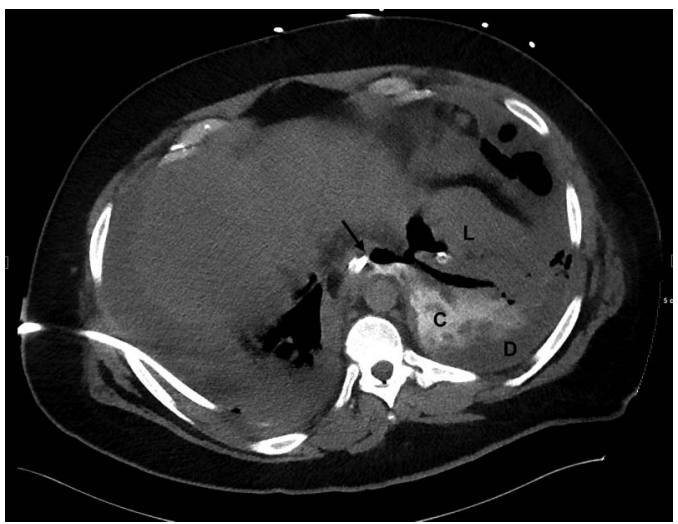

To cite: Atie M, Dunn G Falk GL. BMJ Case Rep Published online: [please include Day Month Year] doi:10.1136/bcr-2016217391

CrossMark
Figure 1 CT scan of the thorax and abdomen-axial view. The black arrow points to the site of oesophageal perforation. C, contrast in pleural cavity; L, collapsed lung; $D$, food debris in pleural space. with on-table NG administered soluble contrast, rather than swallow, for initial diagnosis. Besides diagnosis of the rupture, CT allows assessment of the extent of pleural, mediastinal and abdominal contaminations. CT also directs the performance of interventional radiology allowing precise allocations of drains and punctures. Delayed presentation and time to initiate management are associated with a mortality rate that exceeds $80 \% .^{2}$

A treatment algorithm was published in $2009,{ }^{2}$ based on current level 4 evidence, indicating that all septic patients should be treated surgically, early presentations without sepsis endoscopically and delayed presentations without sepsis conservatively. Griffin $e t a l^{3}$ suggest that conservative management is specifically reserved for delayed presentations with contained, wide-necked perforations without sepsis and for those who demonstrate tolerance to pleural contamination amenable to radiological drainage. Endoscopic treatment, on the other hand, is associated with a significant complication rate. ${ }^{4}$ No provision has been made in published treatment algorithms for patients with delayed presentations who are septic and unfit for surgical intervention. Figure 3 displays our proposed treatment algorithm for patients with Boerhaave's syndrome. The flow chart incorporates the management plan for the delayed unstable patient. Our case report demonstrates that aggressive surgical management remains the main stay of treatment in the latter group of patients once their condition has been stabilised.

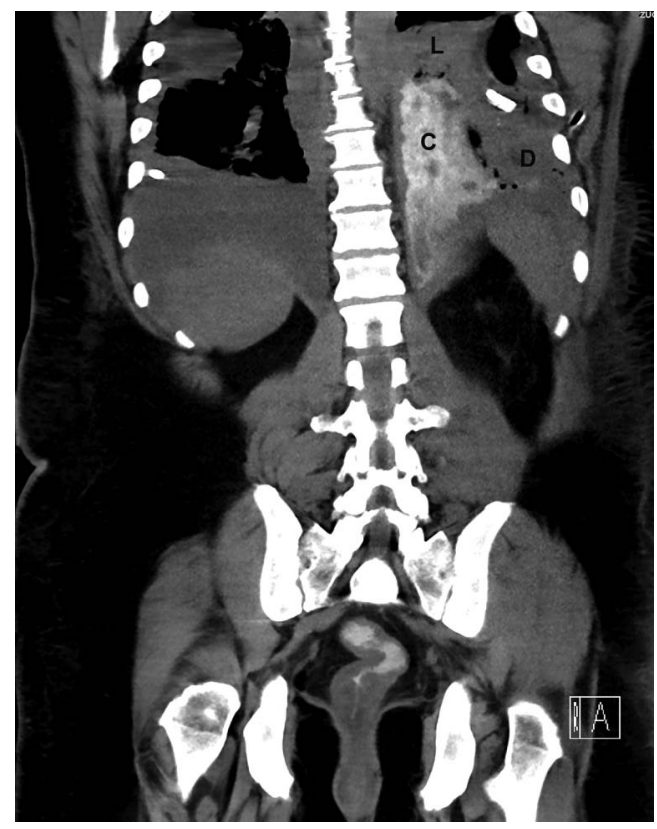

Figure 2 CT scan of the thorax and abdomen-coronal view. C, contrast in pleural cavity; $L$, collapsed lung; $D$, food debris in pleural space. 


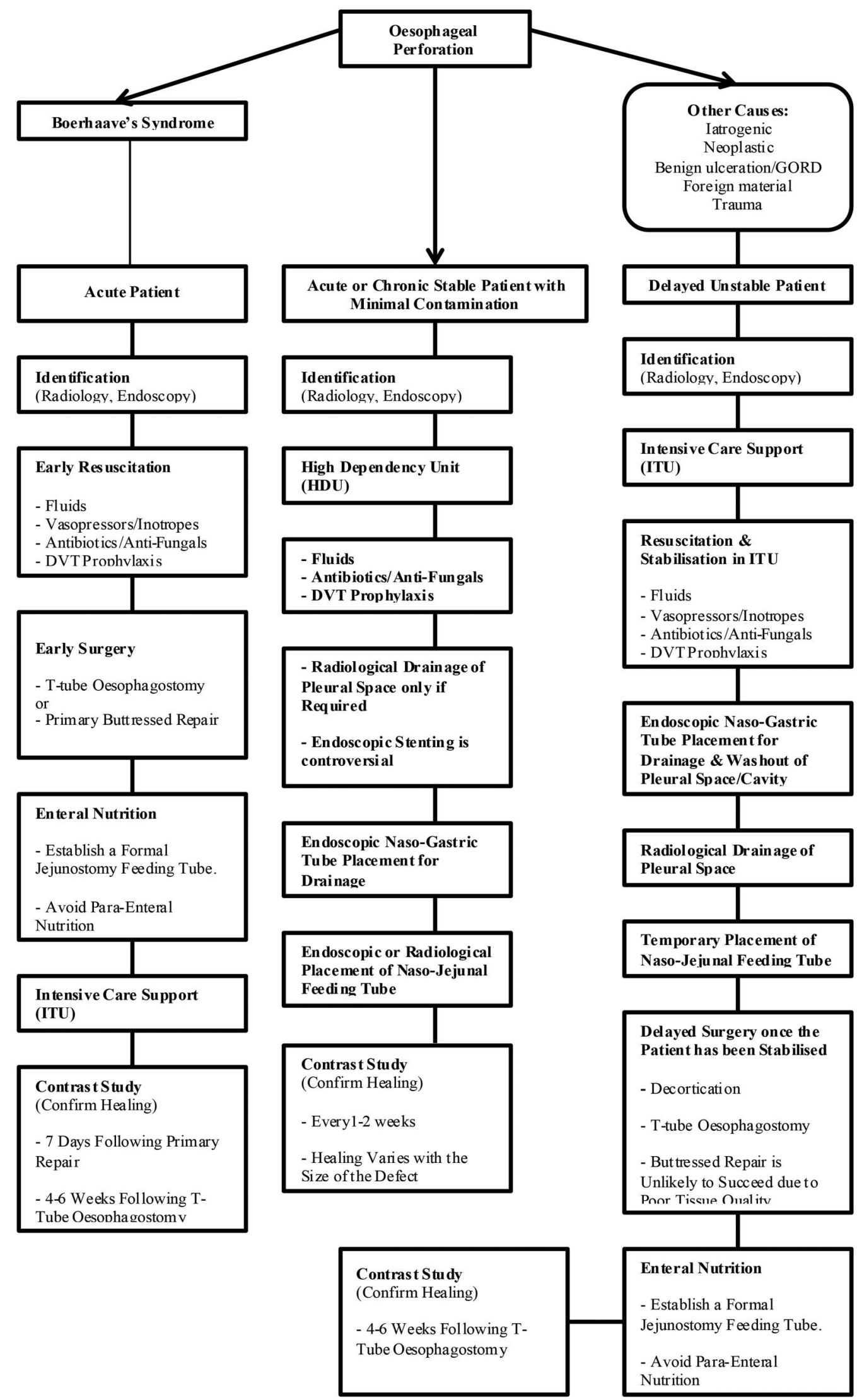

Figure 3 The proposed management plan for the stable, unstable, acute and chronic Boerhaave's syndrome patients. 


\section{Learning points}

- A clinician should highly consider the diagnosis of Boerhaave's syndrome in a septic patient who presents with hydropneumothorax even in the absence of the classical Mackler triad.

- Delayed presentation, an incorrect diagnosis and the lack of prompt treatment significantly increase morbidity and mortality.

- A patient with delayed presentation of Boerhaave's syndrome who is in a stable state can be managed conservatively, but the unstable patient should receive prompt resuscitative treatment until stabilised. Urgent surgery should follow.

Contributors MA made conception and design of the work and participated in data collection, data analysis and interpretation, drafting the article, critical revision of the article, and final approval of the version to be published. GD involved in data analysis and interpretation, critical revision of the article and final approval of the version to be published. GLF involved in data analysis and interpretation, critical revision of the article, and final approval of the version to be published. All of the authors have participated in caring for the patient.

Competing interests None declared.

Patient consent Obtained.

Provenance and peer review Not commissioned; externally peer reviewed.

\section{REFERENCES}

1 Connelly CL, Lamb PJ, Paterson-Brown S. Outcomes following Boerhaave's syndrome. Ann R Coll Surg Engl 2013;95:557-60.

2 de Schipper JP, Pull ter Gunne AF, Oostvogel HJ, et al. Spontaneous rupture of the oesophagus: Boerhaave's syndrome in 2008. Literature review and treatment algorithm. Dig Surg 2009;26:1-6.

3 Griffin SM, Lamb PJ, Shenfine J, et al. Spontaneous rupture of the oesophagus. $\mathrm{Br}$ J Surg 2008;95:1115-20.

4 Salo J, Sihvo E, Kauppi J, et al. Boerhaave's syndrome: lessons learned from 83 cases over three decades. Scand J Surg 2013;102:271-3.

Copyright 2016 BMJ Publishing Group. All rights reserved. For permission to reuse any of this content visit http://group.bmj.com/group/rights-licensing/permissions.

BMJ Case Report Fellows may re-use this article for personal use and teaching without any further permission.

Become a Fellow of BMJ Case Reports today and you can:

- Submit as many cases as you like

- Enjoy fast sympathetic peer review and rapid publication of accepted articles

- Access all the published articles

- Re-use any of the published material for personal use and teaching without further permission

For information on Institutional Fellowships contact consortiasales@bmjgroup.com

Visit casereports.bmj.com for more articles like this and to become a Fellow 